\title{
Case Studies on Enhanced Heat Transfer in a Square Duct with Modified V-Shaped Ribs (MVR): A CFD Analysis
}

\author{
Amnart Boonloi $(\mathbb{D})^{1}$ and Withada Jedsadaratanachai $\mathbb{I D}^{2}$ \\ ${ }^{1}$ Department of Mechanical Engineering Technology, College of Industrial Technology, King Mongkut's University of Technology \\ North Bangkok, Bangkok 10800, Thailand \\ ${ }^{2}$ Department of Mechanical Engineering, School of Engineering, King Mongkut's Institute of Technology Ladkrabang, \\ Bangkok 10520, Thailand
}

Correspondence should be addressed to Withada Jedsadaratanachai; withada.je@kmitl.ac.th

Received 9 August 2021; Accepted 27 December 2021; Published 18 January 2022

Academic Editor: Parviz Ghadimi

Copyright (C) 2022 Amnart Boonloi and Withada Jedsadaratanachai. This is an open access article distributed under the Creative Commons Attribution License, which permits unrestricted use, distribution, and reproduction in any medium, provided the original work is properly cited.

\begin{abstract}
This research presents structural improvement of V-shaped ribs for a tested square duct (TSD). The V-shaped ribs, which are inserted at the middle of the TSD (called type A), and the V-shaped ribs, which are placed on the opposite TSD walls (called type B), are modified to increase the structural stabilization. The effects of rib height to duct height, $b / H=0.05-0.30$; Vshaped bar thickness to duct height, $a / H=0.025$ and 0.050 ; and flow directions (V-Upstream and V-Downstream) are considered. The new design of the V-shaped ribs is called "modified V-shaped ribs or MVR." The present problem is solved by the numerical method (commercial code). The flow and heat transfer features of the TSD are illustrated. The numerical result reveals that the MVR give both flow and heat transfer patterns similarly as the general V-shaped rib. The impinging flows, swirling flows, and disturbing thermal boundary layer, which lead to enhanced heat transfer, are observed. Over the investigated range, the enhanced heat transfer about 18.12 times above the smooth duct with the optimal thermal enhancement factor about 4.16 is detected.
\end{abstract}

\section{Introduction}

Heat exchangers, shell-and-tube heat exchanger, fin-andtube heat exchanger, double pipe heat exchanger, and solar air heater, are important machines for many industries and engineering works. Thus, development of the heat exchangers is a main project for industrial improvement. The heat exchanger development can help about energy conservation of the industries. The energy conservation directly affects production cost of production processes. The heat exchanger development can be done by various techniques. An installation of vortex generators or turbulators into the heat exchanger is one of the techniques to improve thermal performance of the heat exchangers. There are many vortexgenerator types such as rib, baffle, winglet, and roughness surface. Each type of the vortex generators is developed under applications of the heat exchangers. Rib/baffle [1-3] is a type of the vortex generators which always select to help to improve heat transfer rate and efficiency of the heat exchangers, especially V-shaped rib. The V-shaped rib/baffle has high effectiveness to enhance heat transfer rate. The Vshaped rib/baffle had been adapted to support many heating systems. Effects of the $\mathrm{V}$-shaped rib/baffle parameters such as rib height, rib spacing, flow attack angle, and placement for flow and heat transfer features had been investigated by many researchers.

For example, Zhang et al. [4] selected micro-V-shaped ribs and dimples to augment heat transfer ability in a channel. Xiao et al. [5] studied the enhanced heat transfer in a minichannel heat sink with V-ribs for Reynolds number around 3600-6800. Their simulated results showed that the enhanced heat transfer is around $171-355 \%$ when compared with the general channel. Bahiraei et al. [6] opted V-shaped ribs combining with nanofluid to improve heat transfer potentiality in a square channel. The influences of flow attack angles, rib pitches, and rib heights were compared. 
They concluded that the higher rib height and smaller rib spacing give lower exergy destruction and increases the second low efficiency. Jain and Lanjewar [7] presented that the maximum enhanced heat transfer of 2.30 times above the base case is observed for a solar air heater equipped with V-ribs. Jin et al. [8] numerically investigated the augmented heat transfer in a solar air heater with multiple-shaped ribs. Bahiraei et al. [9] simulated the fluid streams and heat transfer features in a square channel inserted with $90^{\circ} \mathrm{V}$-shaped ribs. They summarized that the augmented heat transfer is around $28.3 \%$ when increasing the rib height from 2.5 to $7.5 \mathrm{~mm}$ for the rib pitch of $50 \mathrm{~mm}$. Misra et al. [10] reported the CFD analysis for a triangular solar air heater duct using $\mathrm{V}$-down ribs with multiple gaps and turbulence promoters. Jin et al. $[11,12]$ improved the thermal performance of a solar air heater by using multiple V-shaped ribs. They reported that the thermohydraulic performance factor of 2.43 is observed for the staggered rib [11]. Kumar and Kim [13] numerically studied the Nusselt number and friction factor in an air duct installed with various V-pattern ribs. Singh et al. [14] selected V-down ribs with gaps to enhance heat transfer coefficient in a rectangular duct. The flow attack angles of the rib with a single relative roughness height of 0.043 and relative roughness pitch of 8 were studied. Deo et al. [15] stated that the maximum enhanced Nusselt number of 3.34 times is found for a solar air heater roughened with multigap $\mathrm{V}$-down ribs combined with staggered ribs. Ravi and Saini [16] installed discrete multi-Vshaped and staggered ribs on both sides of an absorber plate to augment Nusselt number in a solar air heater. They concluded that the best Nusselt number ratio is around 4.52. Caliskan and Baskaya [17] improved the heat transfer ability by using V-shaped and convergent-divergent ribs. Singh et al. [18] compared between a solar air heater having discrete V-down ribs and a conventional flat-plate solar air heater.

As discussed in the published works, the V-shaped rib/ baffle is an effective vortex generator for various heat exchangers. The heat transfer rate and thermal performance in the heat exchangers obviously augment when installed with the V-shaped rib/baffle. However, we found that the structural V-shaped rib/baffle is unstable for some systems. The V-shaped rib/baffle [19-21] which is placed on the upper-lower walls always slips from the heat exchanger section, especially the upper V-shaped rib/baffle. The V-shaped rib/baffle [21] which is inserted in the middle of the tested section always moves from their locations (cross-sectional view). Due to the problem, the V-shaped rib/baffle is modified with the main idea to improve the stabilization of the rib/baffle structure. The maintenance and installment are also considered for this modification. The modification is done for both rib/baffle types: (1) the $\mathrm{V}$-shaped rib/baffle which is inserted in the middle of the tested square duct (TSD) and (2) the V-shaped rib/baffle which is placed on the upper-lower TSD walls. The new design of the Vshaped rib/baffle is called modified V-shaped rib (MVR). The influences of MVR dimensions and MVR placements for heat transfer, flow pattern, and thermal performance are considered. A numerical investigation is opted to inves- tigate the TSD installed with the MVR because we would like to know about the heat transfer and flow mechanisms in the tested section. The heat transfer and flow mechanisms in the TSD are significant knowledge for the vortex generator and heat exchanger improvements.

\section{Physical Model of the TSD Installed with the MVR}

The tested section is the TSD equipped with various MVR types as depicted in Figure 1(a). The MVR can be separated into two configurations: (1) "type A" is a combination of the $\mathrm{V}$-shaped rib which is inserted in the middle of the TSD and the V-shaped bar and (2) "type B" is a combination of the Vshaped rib which is placed on the upper-lower TSD wall and the $\mathrm{V}$-shaped bar (see Figure 1(b)). The TSD height, $H$, is equal to the TSD width, $H=W=0.05 \mathrm{~m}$. The V-shaped bar is created with the main aim to increase the stabilization of the vortex generator. The MVR height, $b$, to the TSD height or $b / H$ is varied: $b / H=0.05,0.10,0.15,0.20,0.25$, and 0.30 . The V-shaped bar thickness, $a$, to the TSD height or $a / H$ of 0.025 and 0.05 is considered. The MVR attack angle, $\alpha$, of $30^{\circ}$ is selected for the present work. The distance between the MVR, $P$, to the TSD height or $P / H$ is equal to 1 [19]. The flow directions can be separated into two ways: (1) $\mathrm{V}$-apex of the MVR pointing downstream called "VDownstream (VD)" or $+x$ and (2) V-apex of the MVR pointing upstream called "V-Upstream (VU)" or $-x$. Reynolds number in laminar flow of $100-2000$ is considered in the present research. Periodic length of the numerical model, $L$ , is equal to $H$.

\section{Mathematical Foundation and Numerical Method}

The assumptions, boundary conditions, and initial conditions for the TSD are concluded as follows:

(i) Considering heat transfer mechanism, forced convection of the TSD is measured, while free convection and radiation heat transfer are unconsidered

(ii) Air with $300 \mathrm{~K}$ temperature $(\operatorname{Pr}=0.707)$ is set as the tested fluid. The air is assumed to be incompressible fluid

(iii) The air properties are considered as constant values because the variations of the fluid temperature in TSD are not higher than $10^{\circ} \mathrm{C}\left(\Delta T \leq 10^{\circ} \mathrm{C}\right)$

(iv) Body force is ignored as well as viscous dissipation

(v) No slip wall condition is applied for all TSD surfaces

(vi) Flow and heat transfer of the TSD are set as steady conditions in three dimensions

(vii) Constant temperature around $310 \mathrm{~K}$ is applied for the TSD walls, while the MVR is assumed to be an insulator 


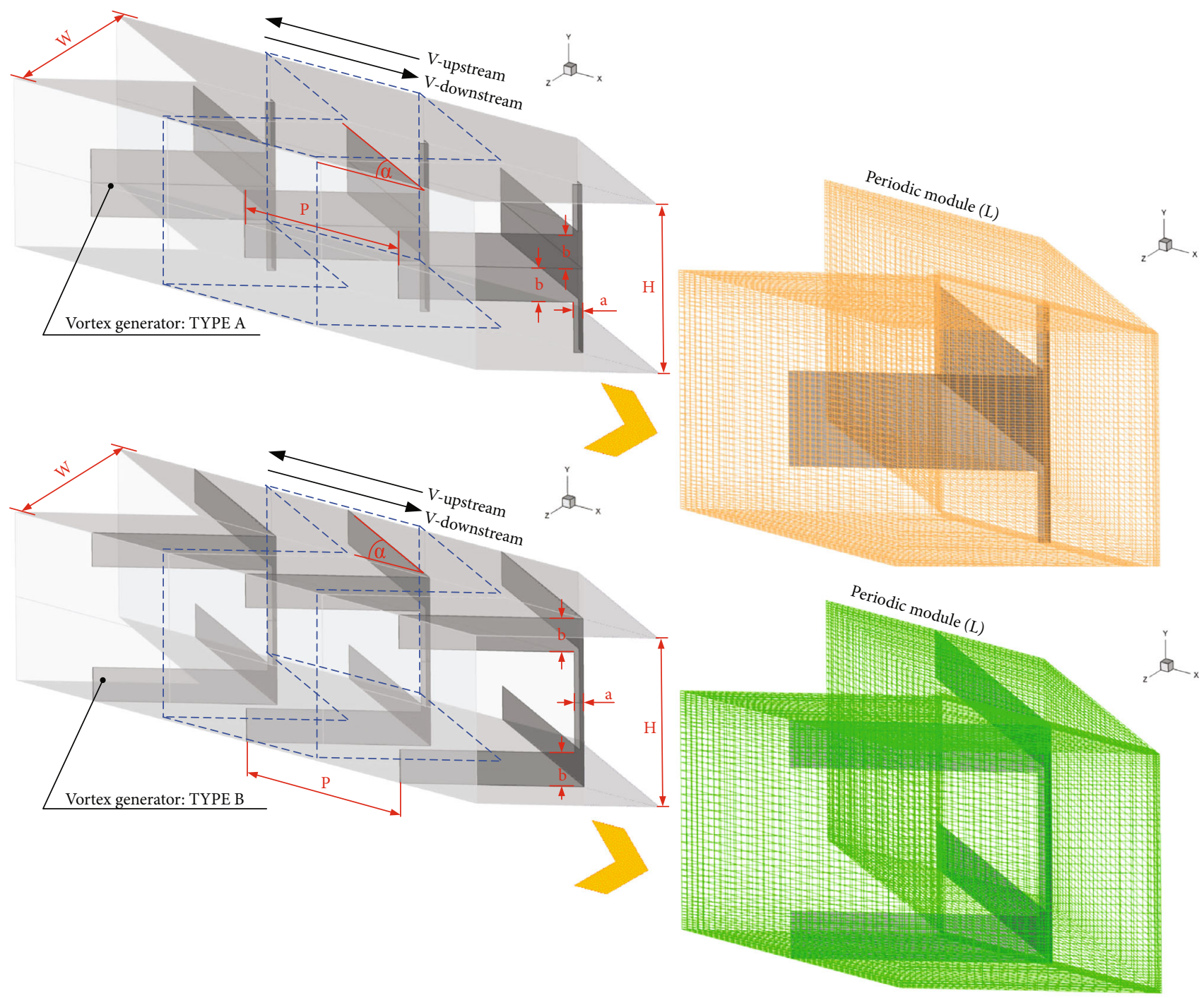

(a)

Figure 1: Continued. 


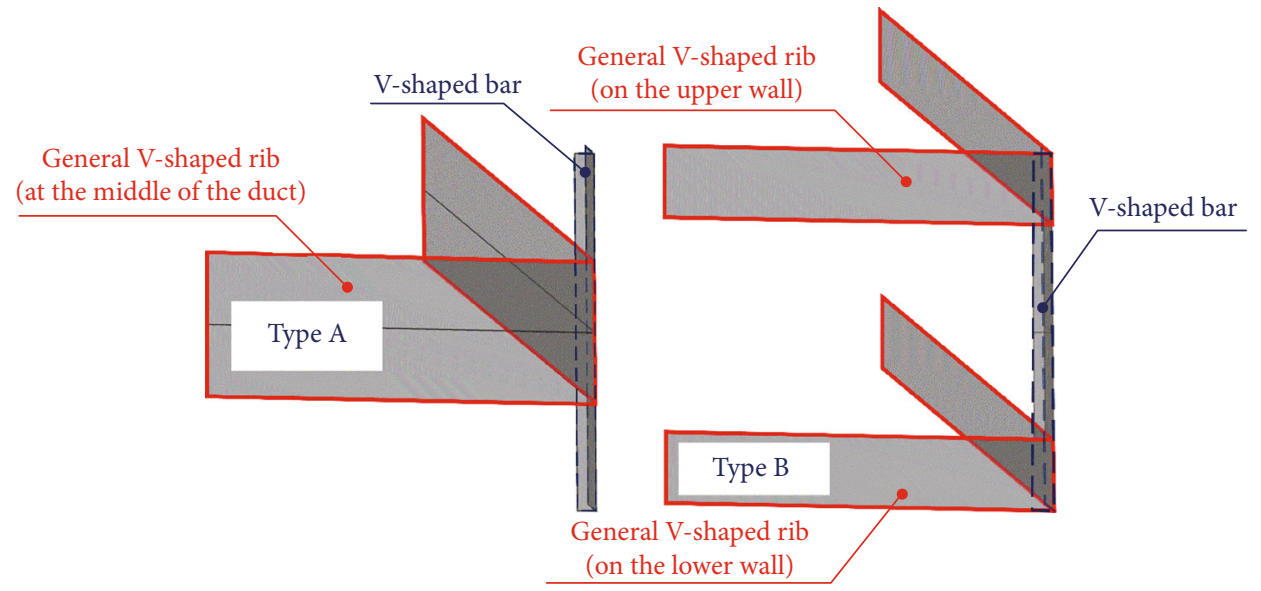

(b)

FIgURE 1: Numerical model: (a) computational domain of the tested duct installed with two MVR types and (b) MVR structure.

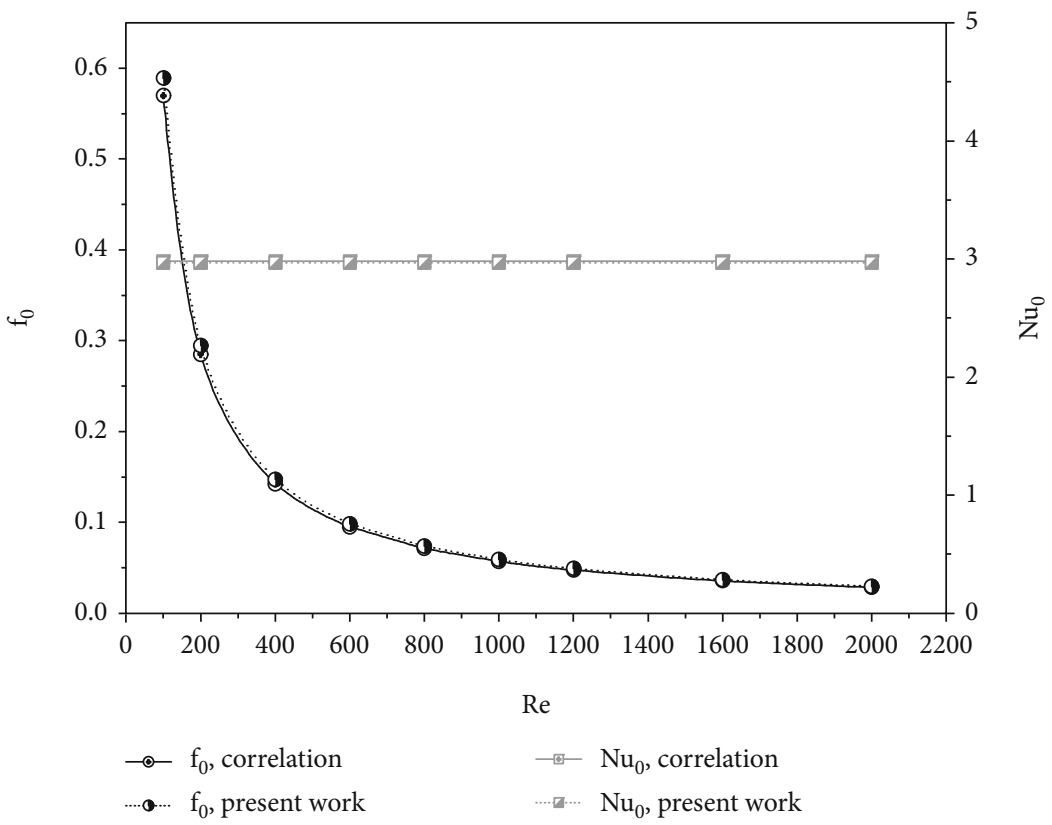

Figure 2: Smooth duct validation.

(viii) Periodic condition is applied for the entry-exit zones of the simulated model

The numerical problem of the TSD installed with the MVR is solved by a commercial code (FLUENT) with the finite volume method. The major equations of this research are the continuity, Navier-Stokes, and energy equations. For the numerical method, the continuity and momentum equations are discretized by power law scheme, while the energy equation is discretized with QUICK scheme. The simulated solutions are accepted to be converged when the normalized residual values are less than $10^{-5}$ for all variables, but less than $10^{-9}$ only for the energy equation.

The continuity equation, momentum equation, and energy equation are shown in Equations (1), (2), and (3), respectively.
Continuity equation

$$
\frac{\partial}{\partial x_{i}}\left(\rho u_{i}\right)=0
$$

Momentum equation

$$
\frac{\partial\left(\rho u_{i} u_{j}\right)}{\partial x_{j}}=-\frac{\partial p}{\partial x_{i}}+\frac{\partial}{\partial x_{j}}\left[\mu\left(\frac{\partial u_{i}}{\partial x_{j}}+\frac{\partial u_{j}}{\partial x_{i}}\right)\right] \text {. }
$$

Energy equation

$$
\frac{\partial}{\partial x_{i}}\left(\rho u_{i} T\right)=\frac{\partial}{\partial x_{j}}\left(\Gamma \frac{\partial T}{\partial x_{j}}\right)
$$




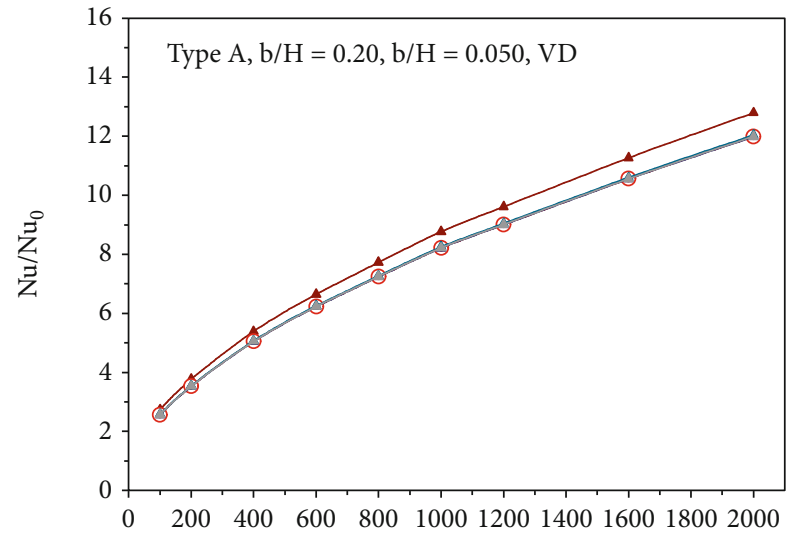

Re

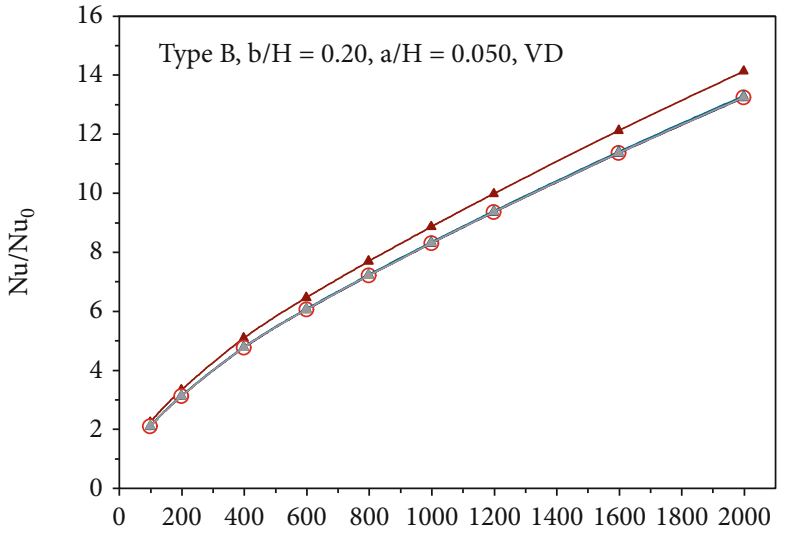

Re

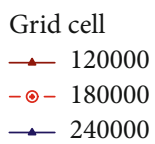

- 360000

$\longrightarrow 480000$

(b)

Figure 3: Grid independence: $\mathrm{Nu} / \mathrm{Nu}_{0}$, for (a) type $\mathrm{A}$ and (b) type $\mathrm{B}$ at $b / H=0.20$ and $a / H=0.050$, VD.

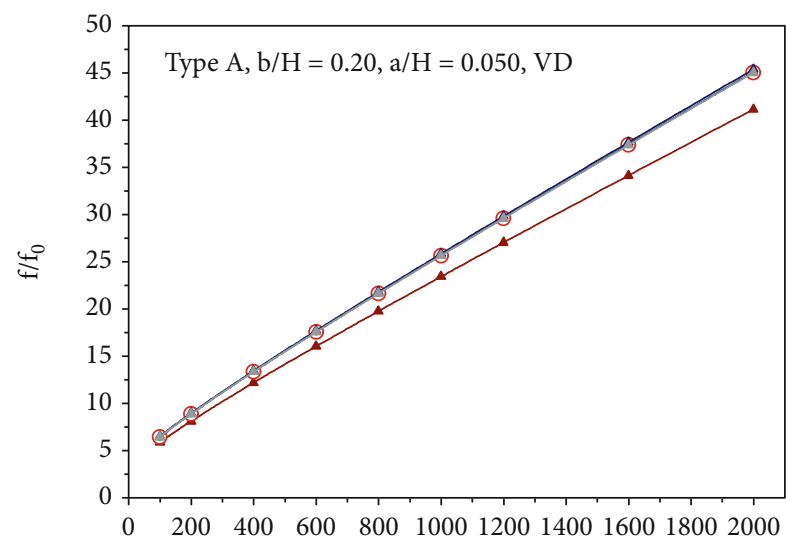

$\operatorname{Re}$

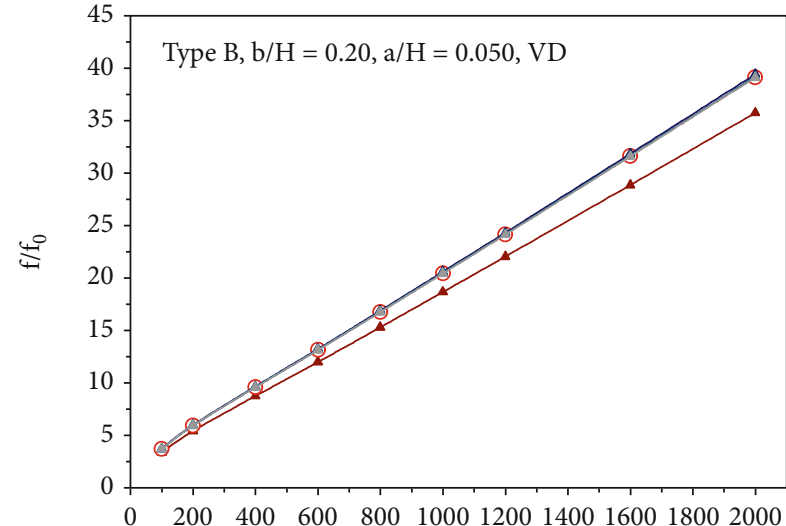

Re

(a)

(b)

FIgURE 4: Grid independence: $f / f_{0}$, for (a) type A and (b) type B at $b / H=0.20$ and $a / H=0.050$, VD.

where $\Gamma$ is the thermal diffusivity and is written as follows:

$$
\Gamma=\frac{\mu}{\operatorname{Pr}}
$$

The air velocity at the TSD inlet is presented by the Reynolds number. The Reynolds number can be calculated as

$$
\operatorname{Re}=\frac{\rho \bar{u} D_{\mathrm{h}}}{\mu} .
$$

The pressure drop across the TSD is shown by friction fac- tor. The friction factor is determined by

$$
f=\frac{(\Delta p / L) D_{\mathrm{h}}}{(1 / 2) \rho \bar{u}^{2}} .
$$

The heat transfer potentiality of the TSD is presented by local Nusselt number and average Nusselt number as Equations (9) and (10), respectively.

$$
q=k_{f}\left(\frac{\partial T}{\partial n}\right)
$$




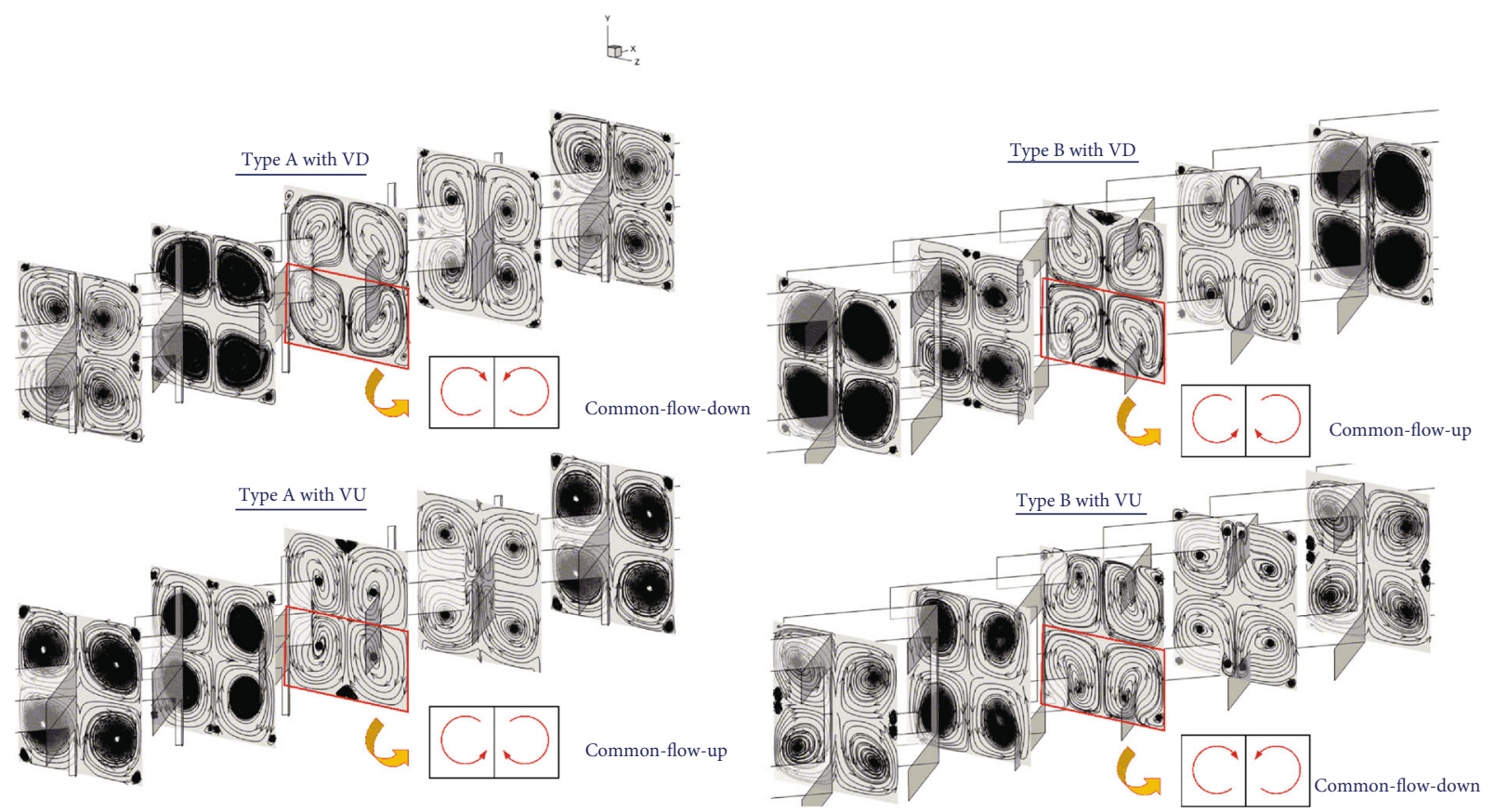

FIGURE 5: Streamline flows in $y$ - $z$ planes of the tested duct with various MVR types and placements at $b / H=0.20, a / H=0.05$, and Re $=800$.

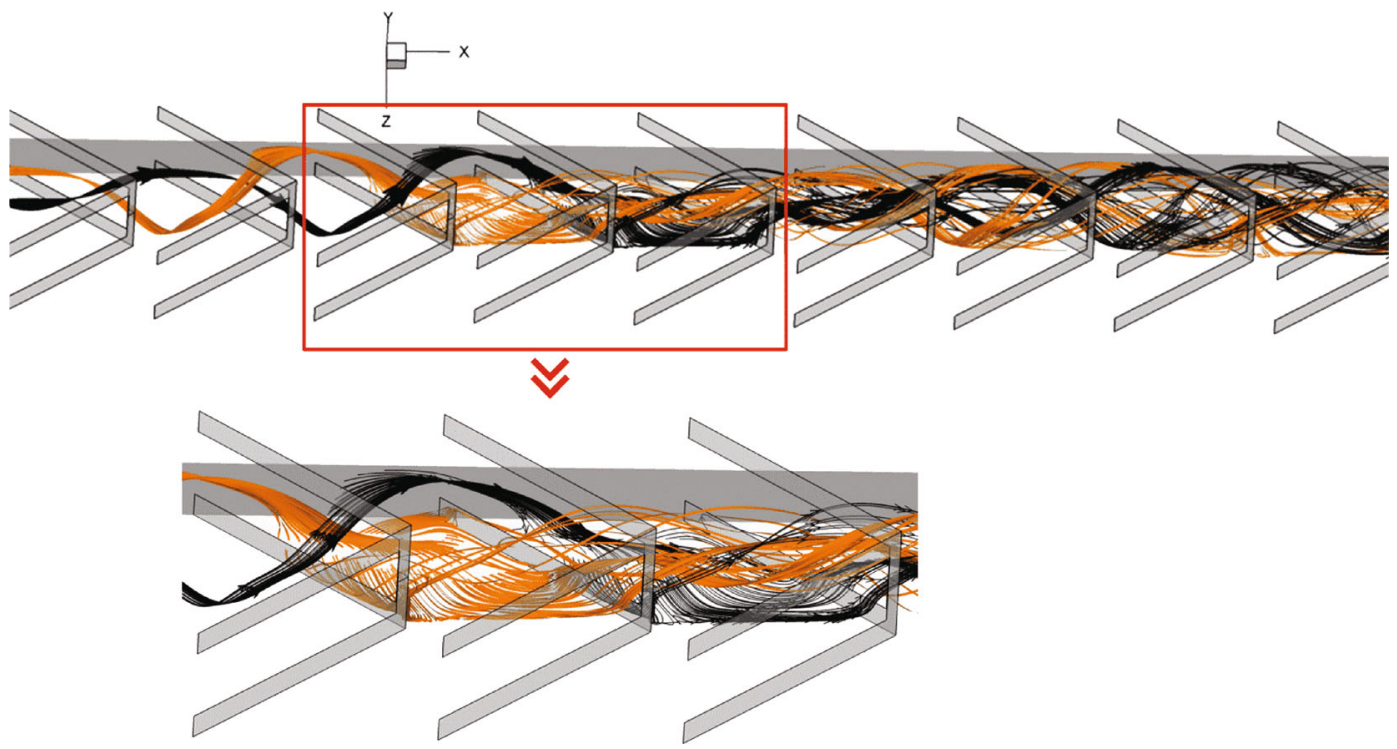

FIGURE 6: Impinging flows in the tested duct.

$$
h_{x}=\frac{q}{T_{\mathrm{w}}-T_{\mathrm{f}}} .
$$

The subscript $\mathrm{w}$ and $\mathrm{f}$ stand for wall and local fluid, respectively, while $n$ is the local coordinate normal to the wall.

$$
\begin{array}{r}
\mathrm{Nu}_{x}=\frac{h_{x} D_{\mathrm{h}}}{k}, \\
\mathrm{Nu}=\frac{1}{A} \int \mathrm{Nu}_{x} \partial A .
\end{array}
$$

The thermal enhancement factor (at an equal pumping force) of the TSD is calculated by Equation (11). The thermal enhancement factor is defined as the ratio between the heat transfer coefficient of the TSD installed with the MVR, $h$, and the heat transfer coefficient of the smooth duct, $h_{0}$.

$$
\mathrm{TEF}=\left.\frac{h}{h_{0}}\right|_{\mathrm{pp}}=\left.\frac{\mathrm{Nu}}{\mathrm{Nu}_{0}}\right|_{\mathrm{pp}}=\frac{\mathrm{Nu} / \mathrm{Nu}_{0}}{\left(f / f_{0}\right)^{1 / 3}}
$$




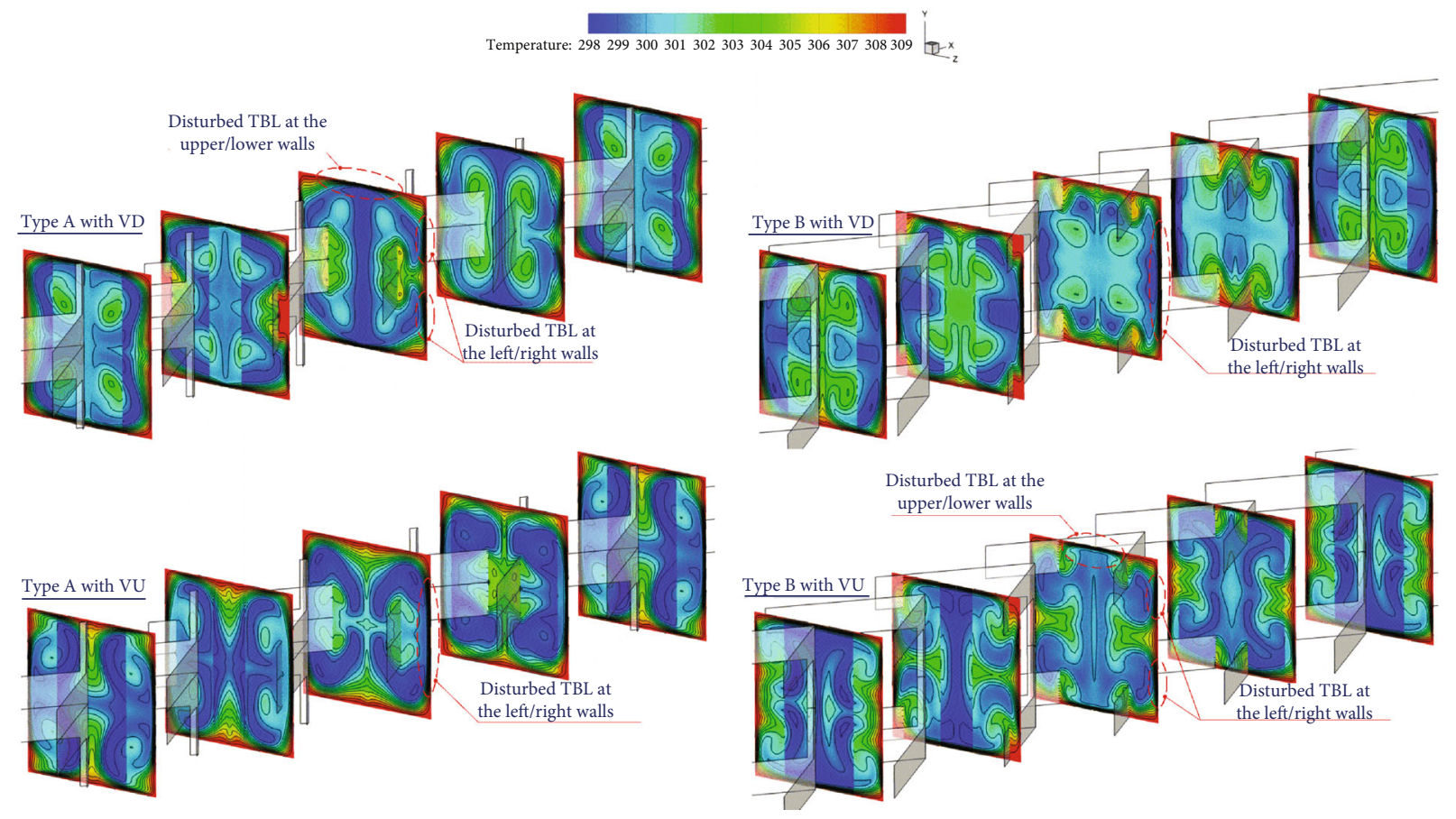

FIGURE 7: Temperature distributions in $y-z$ planes of the tested duct with various MVR types and placements at $b / H=0.20, a / H=0.05$, and $\operatorname{Re}=800$.

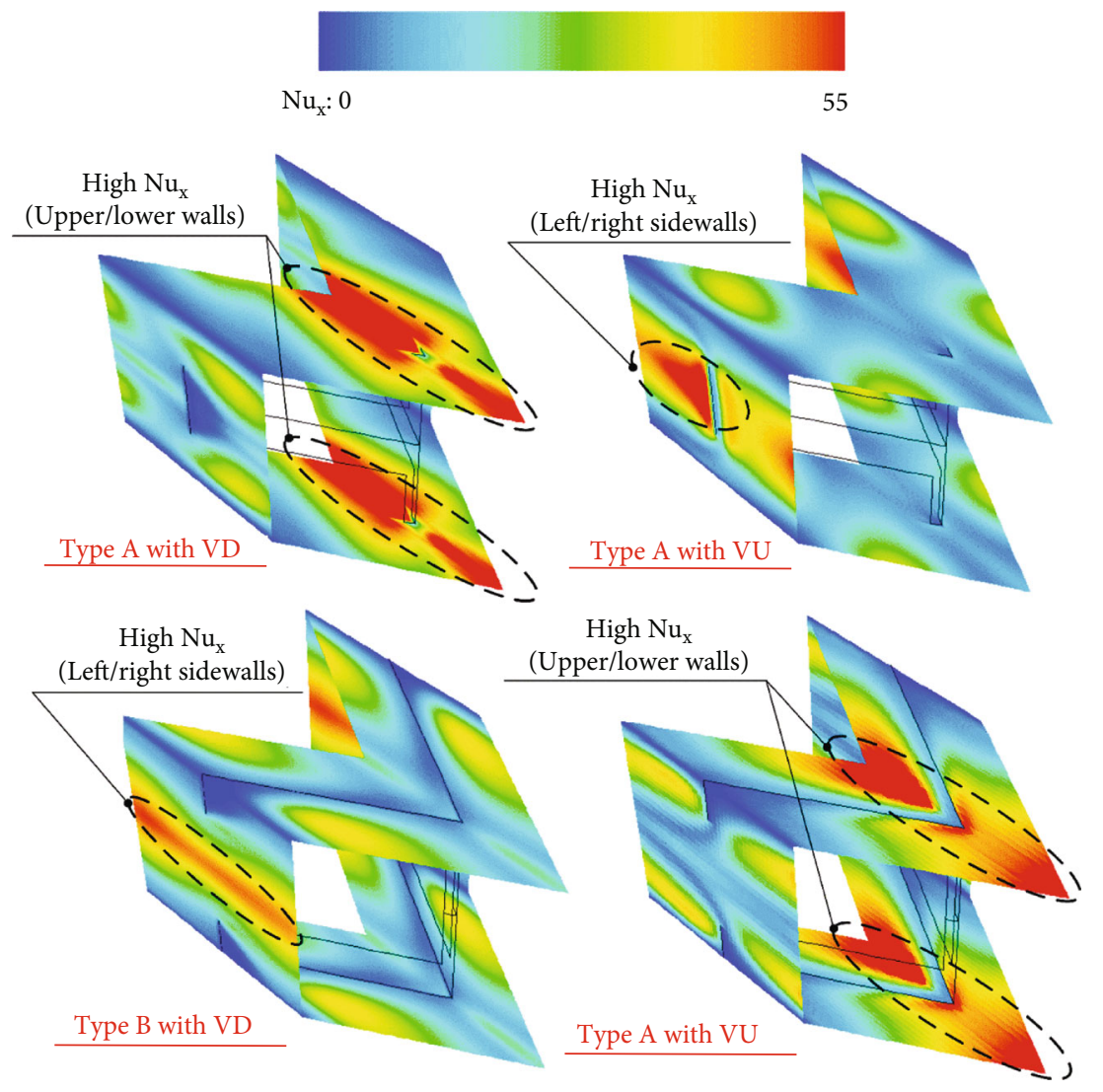

FIGURE 8: $\mathrm{Nu}_{x}$ on the duct walls of the tested duct with various MVR types and placements at $b / H=0.20, a / H=0.05$, and $\mathrm{Re}=800$. 

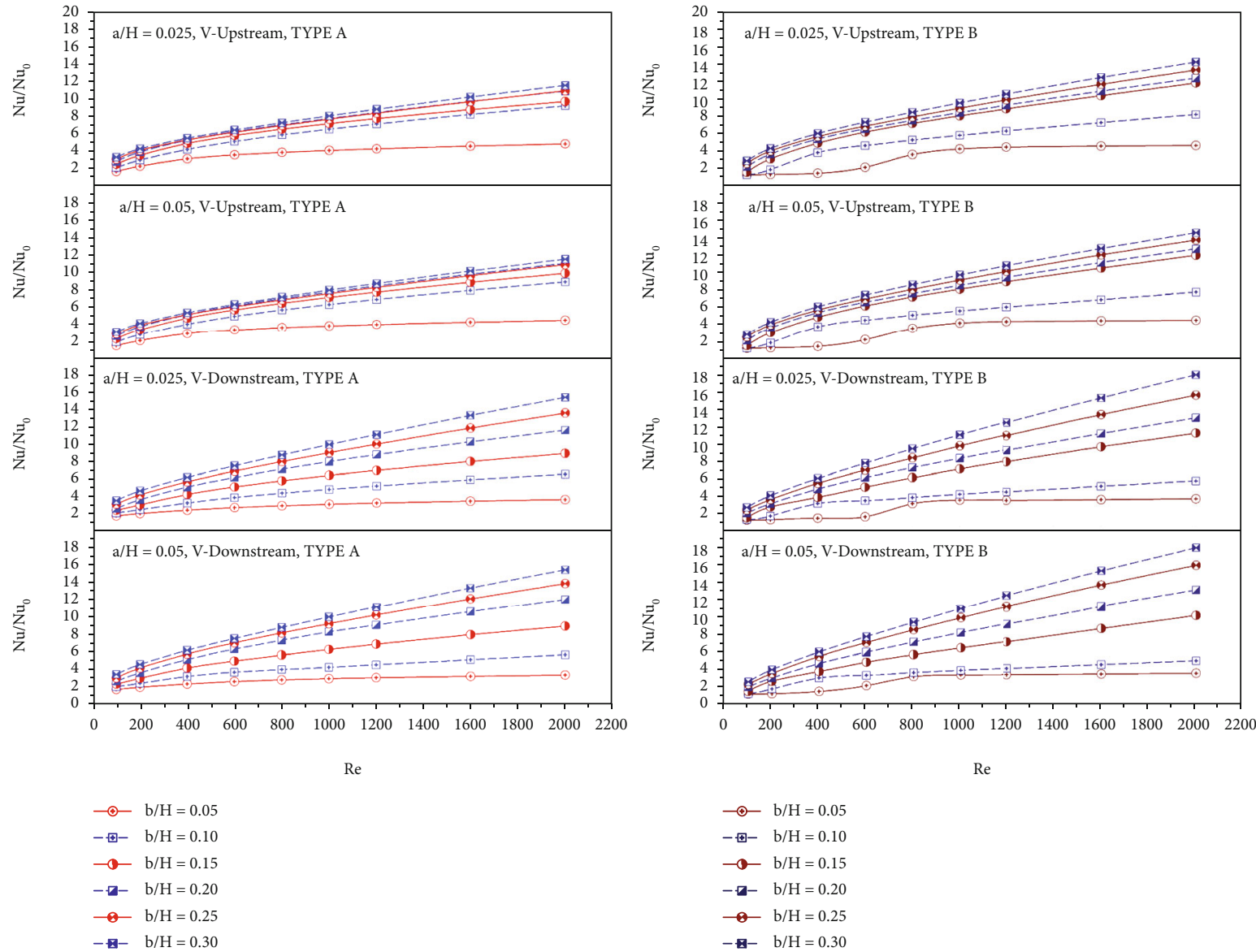

Figure 9: $\mathrm{Nu} / \mathrm{Nu}_{0}$ vs. $\mathrm{Re}$.

\section{Numerical Result}

The numerical results can be reported as three subsections: (1) numerical validation, (2) configurations of flow and heat transfer, and (3) performance evaluation.

4.1. Numerical Validation. For laminar flow, the numerical model is validated by two topics: (1) smooth duct validation and (2) grid independence. For smooth duct validation, the Nusselt number and friction factor of the present smooth duct are compared with the correlation data [22] as depicted in Figure 2. In the figure, it is observed that the present results are in similar trends with the correlation values. The deviations of the Nusselt number and friction factor are not higher than $\pm 10 \%$.

For grid independence, the numerical models (type A and $\mathrm{B}, b / H=0.20, a / H=0.05, \mathrm{VD})$ with five different grids: $120000,180000,240000,360000$, and 480000, are compared as depicted in Figures 3 and 4 for $\mathrm{Nu} / \mathrm{Nu}_{0}$ and $f / f_{0}$, respectively. As the comparison shows, the similar trends for both Nusselt number and friction factor are observed for all grid cells. The increased grid cell much more than 180000 has no impact for the pressure loss and heat transfer. Thus, the numerical model of the TSD equipped with the MVR is created with the 180000 grid cells for all studied cases.
As the results validated, it can be summarized that the numerical model of the TSD has reliability to study the configurations of flow and heat transfer.

4.2. Configuration of Flow and Heat Transfer in the TSD. The streamlines in transverse axis of the TSD are presented as Figure 5 for $b / H=0.20, a / H=0.05$, and $\operatorname{Re}=800$. The MVR generates vortex flows through the TSD for all investigated cases. The flow patterns are similar as the general Vshaped rib with no $\mathrm{V}$-shaped bar. The four main vortex centers and small vortices near the TSD angles and walls are found. The symmetric flows at the upper-lower and leftright parts are seen due to the symmetric MVR. Considering the lower pairs of the vortex flows, counter-rotating flows with common-flow-up are found for the type A MVR with the VU direction and the type B MVR with the VD direction, while the counterrotating flows with common-flowdown are found for the type A MVR with the VD direction and the type B MVR with the VU direction. The vortex center position depends on the MVR heights and types.

The impinged streams on the TSD walls are depicted in Figure 6. Normally, the impinged streams which are a part of the vortex flows are found in all investigated cases. The impinged position in the TSD depends on the MVR types and flow directions. 

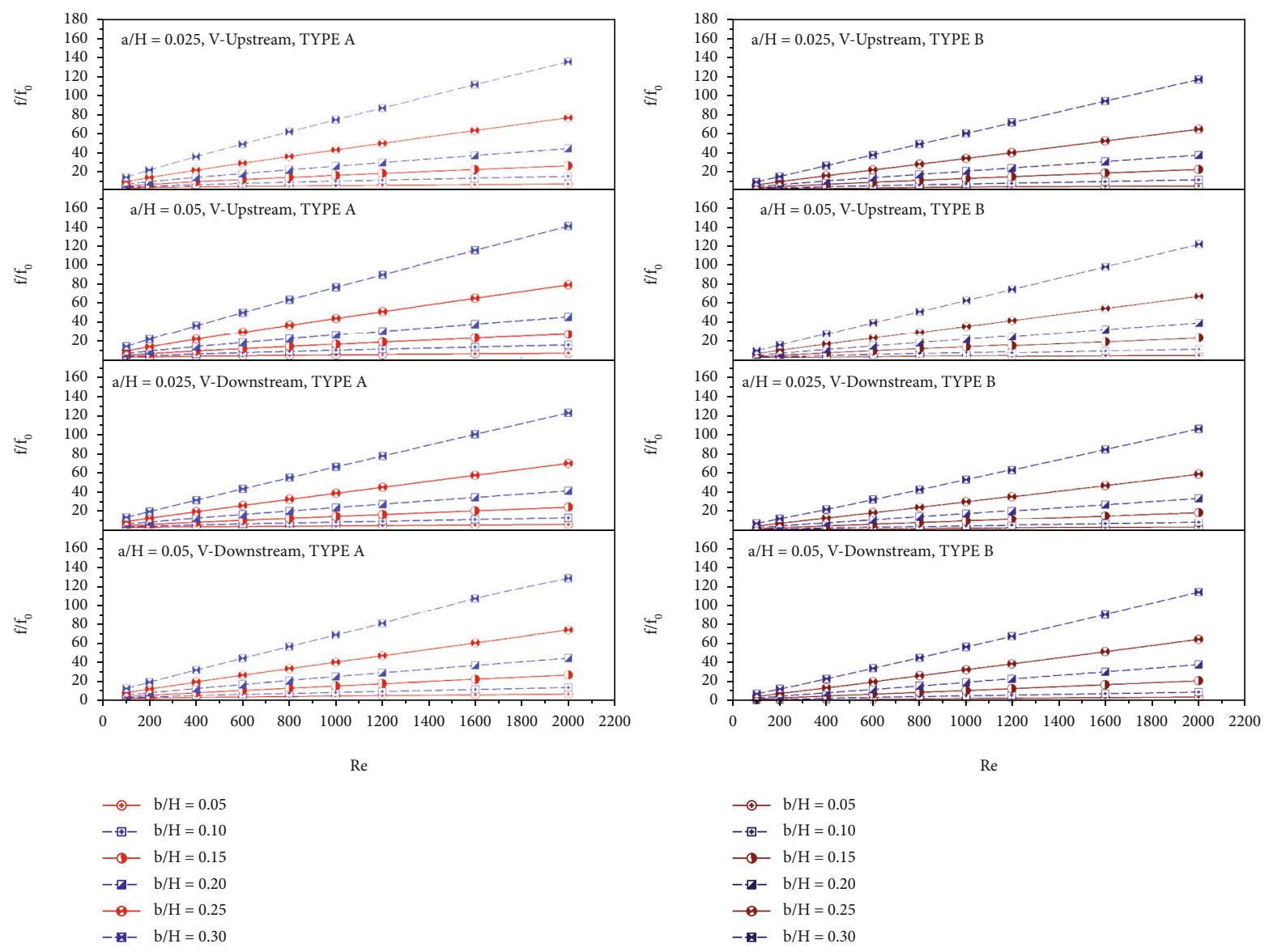

Figure 10: $f / f_{0}$ vs. Re.

The vortex flows and impinged streams in the TSD are an important mechanism for the improved heat transfer. The vortex flows and impinged streams help better flow mixing and disturbed thermal boundary layer. The better flow mixing and the disturbed thermal boundary layer are two main factors for the heat transfer development.

The heat transfer mechanisms of the TSD are presented by the fluid temperature in transverse axis and local Nusselt number on the TSD walls. Figure 7 plots the temperature distributions in the transverse axis in the TSD. Generally, the better fluid distributions are observed in all studied cases. The disturbed thermal boundary layer is also found near the TSD walls. The configurations of the disturbed thermal boundary layer depend on the MVR types and flow directions.

The Nusselt number distributions on the TSD walls are shown in Figure 8. In the figure, the highest heat transfer (red contour) is observed at the upper-lower walls for the type A MVR with the VD direction and the type B MVR with the VU direction. For the type A MVR with the VU direction and the type B MVR with the VD direction, the best Nusselt number (red contours) is detected at the leftright sidewalls. The highest Nusselt number on the TSD walls is due to the disturbed thermal boundary layer which is acted by the impinged flow.
4.3. Performance Evaluation. There are three subparts: enhanced heat transfer, augmented pressure loss, and efficiency, for the thermal performance analysis. The enhanced heat transfer in the TSD is presented by the Nusselt number ratio $\left(\mathrm{Nu} / \mathrm{Nu}_{0}\right)$, while the augmented pressure loss is reported by the friction factor ratio $\left(f / f_{0}\right)$. The installation of the MVR in the TSD leads to the increased heat transfer rate and friction loss. Therefore, a merit for the MVR installation is considered in terms of thermal enhancement factor (TEF).

Figure 9 presents the relations of the $\mathrm{Nu} / \mathrm{Nu}_{0}$ versus $\mathrm{Re}$ for the TSD installed with the MVR. Normally, the heat transfer rate enhances when augmenting the Reynolds number and MVR height due to the increased vortex strength. The vortex strength directly affect the enhanced heat transfer rate. The $a / H=0.05$ performs slightly greater heat transfer rate than the $a / H=0.025$ for all MVR types and flow directions. The VD direction gives an upper Nusselt number than the VU direction. In comparison for the MVR type, the type B MVR provides a higher Nusselt number than the type A MVR. Over the investigated range, the $\mathrm{Nu} / \mathrm{Nu}_{0}$ is around 1.45-15.45 and 1.05-18.12 for the type A and B MVR, respectively.

The relations of the $f / f_{0}$ with Re in the TSD located with the MVR are presented as Figure 10. As seen in the figure, 

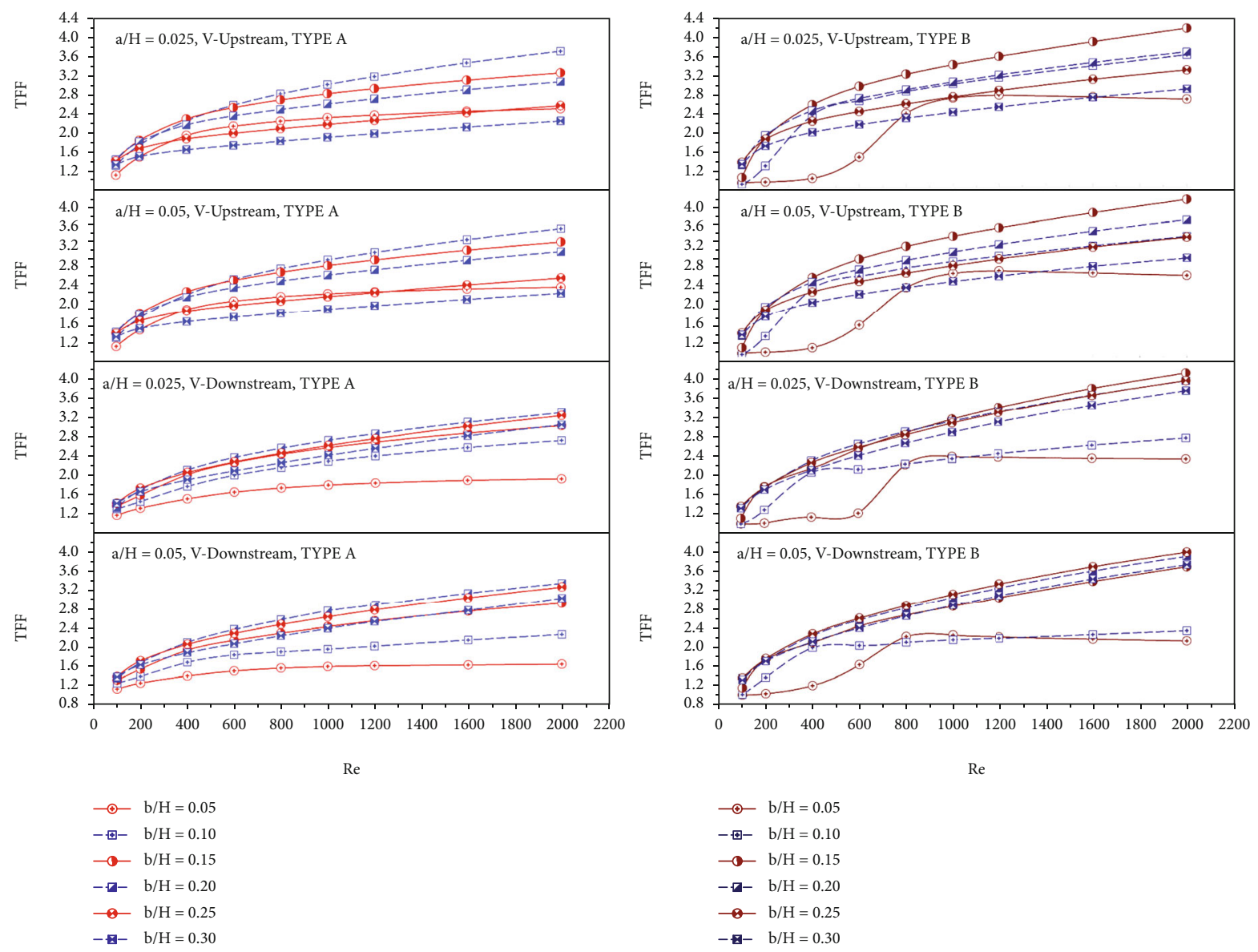

Figure 11: TEF vs. Re.
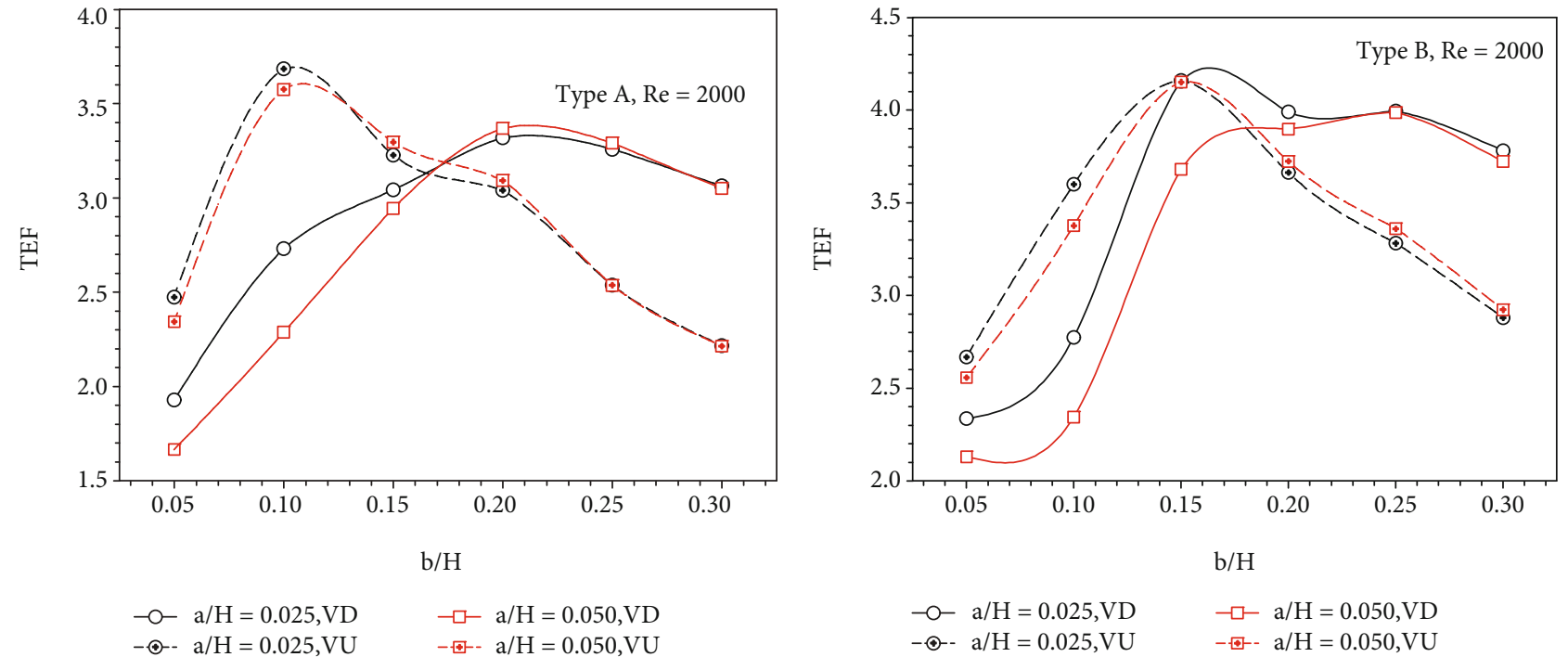

$$
\begin{array}{ll}
-\mathrm{O} \text { a/H }=0.025, \mathrm{VD} & -\square \mathrm{a} / \mathrm{H}=0.050, \mathrm{VD} \\
-\odot-\mathrm{a} / \mathrm{H}=0.025, \mathrm{VU} & - \text { - } \mathrm{a} / \mathrm{H}=0.050, \mathrm{VU}
\end{array}
$$

(a) (b)

Figure 12: TEF vs. $b / H$ for (a) type A and (b) type B. 
the $f / f_{0}$ increases when rising the Reynolds number and MVR height. The $a / H=0.05$ performs slightly higher friction loss than the $a / H=0.025$. The VU direction gives upper pressure loss than the VD direction. The type A MVR provides more friction loss than the type B MVR. In the investigated range, the $f / f_{0}$ is found to be around 2.40-141.75 and 1.55-122.14 for the type A and B MVR, respectively.

The variations of the TEF with Re for the TSD installed with the MVR are plotted as Figure 11. The addition of the MVR gives more thermal performance than the plain duct for all investigated cases. The variated $a / H$ has slightly affected the variated TEF. The type A MVR performs lower TEF than the type B MVR. The best TEF of 4.16 is found at the type B MVR, $b / H=0.15$ and VU.

The variations of the TEF vs. $b / H$ at $R e=2000$ for the type A and B MVR are plotted in Figures 12(a) and 12(b), respectively. For the type A MVR, the best TEF is observed at $b / H$ $=0.10$ and 0.20 , for the V-Upstream and V-Downstream, respectively. For the type $\mathrm{B}$ MVR, the optimum TEF is detected at the $b / H=0.15$, except for the $a / H=0.05$ of the $\mathrm{V}$-Downstream which performs the best TEF at $b / H=0.25$.

\section{Conclusion}

Numerical predictions on heat transfer and flow features in the TSD installed with the MVR are reported. The effects of the MVR heights, MVR types, V-shaped bar sizes, and MVR placements are considered for $\mathrm{Re}=100-2000$. As the simulated results show, the summarization can be stated as follows:

(i) The structural flow and heat transfer in the TSD installed with the MVR are similarly as the general V-shaped baffle/rib. The mechanisms, vortex streams, impinged streams, and disturbed thermal boundary layer, are observed in the TSD

(ii) The maximum heat transfer rate of 18.12 times over the smooth duct is found for the type B MVR. The best TEF of 4.16 is detected for the TSD installed with the type B MVR at $b=0.15 \mathrm{H}$ and $a=0.025 \mathrm{H}$ with the VU direction

(iii) In comparison with the general V-shaped baffle/rib [19-21], the MVR gives both heat transfer rate and thermal performance nearly as the general types. The structural MVR has more stability than the general V-shaped baffle/rib when inserted in the real heating system

\section{Nomenclature}

a: $\quad \mathrm{V}$-bar thickness, $\mathrm{m}$

$b$ : $\quad$ MVR height, $\mathrm{m}$

$D_{\mathrm{h}}$ : Hydraulic diameter of the duct, $\mathrm{m}$

$f$ : Friction factor

$H$ : Square duct height, $\mathrm{m}$

$h$ : Convective heat transfer coefficient, $\mathrm{W} \mathrm{m}^{-2} \mathrm{~K}^{-1}$

$k$ : Thermal conductivity, $\mathrm{W} \mathrm{m} \mathrm{m}^{-1} \mathrm{~K}^{-1}$

$L$ : Numerical model length
Nu: Nusselt number $\left(=h D_{\mathrm{h}} / k\right)$

$p$ : $\quad$ Static pressure, $\mathrm{Pa}$

Re: Reynolds number

T: $\quad$ Temperature, $\mathrm{K}$

$\bar{u}$ : Mean velocity in channel, $\mathrm{m} \cdot \mathrm{s}^{-1}$.

Greek Letters

$\alpha: \quad$ Flow attack angle, degree

TEF: Thermal enhancement factor $\left(=\left(\mathrm{Nu} / \mathrm{Nu}_{0}\right) /\left(f / f_{0}\right)^{1 / 3}\right)$

$\rho$ : $\quad$ Density, $\mathrm{kg} \cdot \mathrm{m}^{-3}$.

Subscript

0: Smooth square channel

pp: Pumping power.

\section{Data Availability}

No data were used to support this study.

\section{Conflicts of Interest}

The authors declare that they have no conflicts of interest.

\section{Acknowledgments}

The authors would like to acknowledge Assoc. Prof. Dr. Pongjet Promvonge for suggestions. This research was funded by King Mongkut's University of Technology North Bangkok, Contract no. KMUTNB-65-BASIC-18.

\section{References}

[1] A. Qayoum and P. Panigrahi, "Experimental investigation of heat transfer enhancement in a two-pass square duct by permeable ribs," Heat Transfer Engineering, vol. 40, no. 8, pp. 640-651, 2019.

[2] A. Rasool and A. Qayoum, "Numerical analysis of heat transfer and friction factor in two-pass channels with variable rib shapes," International Journal of Heat and Technology, vol. 36, no. 1, pp. 40-48, 2018.

[3] A. Rasool and A. Qayoum, "Numerical investigation of fluid flow and heat transfer in a two-pass channel with perforated ribs," Pertanika Journal of Science \& Technology, vol. 26, no. 4, pp. 2009-2029, 2018.

[4] P. Zhang, Y. Rao, Y. Xie, and M. Zhang, "Turbulent flow structure and heat transfer mechanisms over surface vortex structures of micro V-shaped ribs and dimples," International Journal of Heat and Mass Transfer, vol. 178, article 121611, 2021.

[5] H. Xiao, Z. Liu, and W. Liu, "Turbulent heat transfer enhancement in the mini-channel by enhancing the original flow pattern with v-ribs," International Journal of Heat and Mass Transfer, vol. 163, article 120378, 2020.

[6] M. Bahiraei, N. Mazaheri, and H. Moayedi, "Employing Vshaped ribs and nanofluid as two passive methods to improve second law characteristics of flow within a square channel: a two-phase approach," International Journal of Heat and Mass Transfer, vol. 151, article 119419, 2020.

[7] P. K. Jain and A. Lanjewar, "Overview of V-RIB geometries in solar air heater and performance evaluation of a new V-RIB geometry," Renewable Energy, vol. 133, pp. 77-90, 2019. 
[8] D. Jin, S. Quan, J. Zuo, and S. Xu, "Numerical investigation of heat transfer enhancement in a solar air heater roughened by multiple V-shaped ribs," Renewable Energy, vol. 134, pp. 78-88, 2019.

[9] M. Bahiraei, N. Mazaheri, Y. Hosseini, and H. Moayedi, “A two-phase simulation for analyzing thermohydraulic performance of $\mathrm{Cu}$-water nanofluid within a square channel enhanced with $90^{\circ} \mathrm{V}$-shaped ribs," International Journal of Heat and Mass Transfer, vol. 145, article 118612, 2019.

[10] R. Misra, J. Singh, S. K. Jain et al., "Prediction of behavior of triangular solar air heater duct using V-down rib with multiple gaps and turbulence promoters as artificial roughness: a CFD analysis," International Journal of Heat and Mass Transfer, vol. 162, article 120376, 2020.

[11] D. Jin, J. Zuo, S. Quan, S. Xu, and H. Gao, “Thermohydraulic performance of solar air heater with staggered multiple Vshaped ribs on the absorber plate," Energy, vol. 127, no. 15, pp. 68-77, 2017.

[12] D. Jin, M. Zhang, P. Wang, and S. Xu, "Numerical investigation of heat transfer and fluid flow in a solar air heater duct with multi V-shaped ribs on the absorber plate," Energy, vol. 89, pp. 178-190, 2015.

[13] A. Kumar and M. H. Kim, "Heat transfer and fluid flow characteristics in air duct with various $\mathrm{V}$-pattern rib roughness on the heated plate: a comparative study," Energy, vol. 103, no. 15, pp. 75-85, 2016.

[14] S. Singh, S. Chander, and J. S. Saini, "Investigations on thermohydraulic performance due to flow-attack-angle in $\mathrm{V}$-down rib with gap in a rectangular duct of solar air heater," Applied Energy, vol. 97, pp. 907-912, 2012.

[15] N. S. Deo, S. Chander, and J. S. Saini, "Performance analysis of solar air heater duct roughened with multigap V-down ribs combined with staggered ribs," Renewable Energy, vol. 91, pp. 484-500, 2016.

[16] R. K. Ravi and R. P. Saini, "Nusselt number and friction factor correlations for forced convective type counter flow solar air heater having discrete multi $\mathrm{V}$ shaped and staggered rib roughness on both sides of the absorber plate," Applied Thermal Engineering, vol. 129, no. 25, pp. 735-746, 2018.

[17] S. Caliskan and S. Baskaya, "Experimental investigation of impinging jet array heat transfer from a surface with Vshaped and convergent-divergent ribs," International Journal of Thermal Sciences, vol. 59, pp. 234-246, 2012.

[18] S. Singh, S. Chander, and J. S. Saini, "Exergy based analysis of solar air heater having discrete $\mathrm{V}$-down rib roughness on absorber plate," Energy, vol. 37, no. 1, pp. 749-758, 2012.

[19] P. Promvonge, W. Jedsadaratanachai, S. Kwankaomeng, and C. Thianpong, "3D simulation of laminar flow and heat transfer in V-baffled square channel," International Communications in Heat and Mass Transfer, vol. 39, no. 1, pp. 85-93, 2012.

[20] A. Boonloi and W. Jedsadaratanachai, "Thermal performance analysis and empirical correlations for laminar forced convection over $30^{\circ} \mathrm{V}$-baffled square channel," Advances in Mechanical Engineering, vol. 6, Article ID 930272, 2014.

[21] A. Boonloi and W. Jedsadaratanachai, "Effect of location in transverse plane for 45-degree V-baffle on flow and heat transfer mechanisms in a square channel," Frontiers in Heat and Mass Transfer, vol. 11, no. 29, 2018.

[22] Y. A. Cengel and A. J. Ghajar, Heat and Mass Transfer: Fundamentals \& Applications, Fifth Edition in SI Units, McGraw-Hill Education, 2015. 